\title{
The Implementation of the Multiperiod Mean-Variance for Asset Allocation of Pension Fund
}

\author{
Rudy Irawan ${ }^{1, *}$ Bona C. Siahaan ${ }^{2}$ \\ ${ }^{1}$ Universitas Indonesia \\ ${ }^{2}$ Universitas Indonesia \\ *Corresponding author. rudyirawan@gmail.com
}

\begin{abstract}
This paper investigates the application of multi-period mean-variance methods for optimal asset allocation in pension fund institutions by considering mortality factors and changes in contributions. The selection of assets used to find portfolios is using Treasury Bills as a risk-free asset and using stock included in the LQ45 index as risk assets that have the best performance during the period 2014 - 2018. The multi-period mean-variance method's main purpose is to obtain the minimum variance with optimal returns at the end of the period. This result indicates that the smallest return is owned by the asset allocation model without contribution because, without additional membership fees, the amount of funds that can be invested is more limited. Hence, the ex-pected wealth terminal is smaller than other asset allocation models. The asset allocation without the mortality factor gives higher expected terminal wealth compared to other asset allocation models. This is because the absence of mortality factor in the pension fund investment will not be forced to stop before the retirement pe-riod ends so that the portfolio return obtained is higher than other asset allocation models. While the asset al-location model using the risk-free asset as references has a higher risk with the same return compared with as-set allocation using risk assets as a reference. This indicates that the asset reference used affects the return and risk on the allocation of assets of the Pension Fund at the end of the period investment.
\end{abstract}

Keywords: Multiperiod Mean Variance, Asset Allocation, Institutions.

\section{INTRODUCTION}

\subsection{Background}

Pension Funds are legal entities that manage and run programs that promise retirement benefits. The Pension Fund manages funds originating from employers and/or participants and develops these funds through investments to ensure participants' welfare during retirement [1]. In managing their funds, the employer pension fund institution can adopt a Defined Benefit system or Defined Contribution. There are several consequences if the company uses this defined benefit pension scheme. Namely, pension contributions paid by employees are smaller than the defined contribution system scheme. Even retirees still receive a monthly salary as when they were still actively working. For companies, in the event of a shortage of pension funds due to fewer contributions due to decreased number of employees or less optimal investment returns, the company must cover the shortfall [2]. Costs incurred as a result of covering the lack of funds are a burden for the employer company. The Defined Contribution Pension Program is a pension plan whose contributions are set in the Pension Fund regulations, and all contributions and development results are recorded in the accounts of each participant as a pension benefit [2]. Defined Contribution Pension Plan contributions come from employees or with additional companies, which then accumulate and are invested by pension fund management institutions where the investment proceeds are paid to employees or participants when they are about to retire.

For employers who use a defined contribution scheme, there is no obligation to close or take over investment risk if the investment returns are not optimal [2]. Thus, employees' pension benefits depend on the pension fund management institution's ability to manage the funds received. This has caused the number of pension funds received to be greater or smaller than the benefits of the defined benefit pension plan. Many 
companies that leave the defined benefit system are defined as a contribution system because of the immense burden [1]. In addition, many companies have transferred their pension plans to the Financial Institution Pension Fund (DPLK) because this is not effective if managed by themselves, but also because there is a burden that must be borne to cover the cost of managing a large pension fund [3].

In general, the investment strategy focuses on getting an efficient portfolio defined as a portfolio that can provide maximum returns at a certain level of risk or a portfolio that can provide minimal risk at a certain level of return. For pension fund portfolios, there is a preference to focus on portfolios that can provide minimal risk at a certain level of return because of pension funds' characteristics as they approach retirement. The expected risk must be smaller to avoid a decline in investment value. Minimize risk at the end of the investment period [4]. Pension funds have characteristics in which the period of contributions to participant contributions is generally multiperiodic and extended, due to the prospect of promotion, economic conditions, and the number of employees in the company that changes both because employees retire, experience death or other causes so that the contribution of pension contributions also changes in each period. Although there are many studies in the literature about the selection of pension portfolio assets, currently, research on the issue of asset selection in the pension fund portfolio by taking into account mortality and changes in membership fees is still very limited [3]. Asset selection to reduce risk in a portfolio generally uses the method introduced [5]. The method introduced by Markowitz suggests that investment participants make investment placements in several types of investment portfolios or diversification so that if the value of an investment falls, the value of other investments is expected to increase. Profits derived from the increase in investment value can cover the loss investment that occurs [6].

The Portfolio Theory introduced by Markowitz is the formation of a portfolio only for single periods that are easily understood and resolved using a mean-variance model. However, this model is not suitable if applied by investment institutions with multiperiod portfolio strategies that must invest funds received at any time and must also rebalance the allocation of assets in the portfolio from time to time [7]. Pension Fund is a nonbank investment institution that should actively monitor and rebalance the portfolio asset allocation held regularly to avoid or minimize risk and optimize portfolio returns [8]. Based on reality, Pension Funds that are rebalancing multiperiod asset allocations produce higher returns than rarely rebalancing. Based on these conditions, we need a method that can help Pension Funds to be able to periodically multiply asset assets, where one method that can be used is mean-variance multiperiod. Discussion of portfolio optimization with multiperiod mean-variance was introduced by in reference [9]. [10] informs that finding a multiperiod portfolio optimization solution is very difficult and complicated. Nevertheless, then along with the development of computers can help solve these problems, including using dynamic programming with the Bellman equation [4], the Monte Carlo algorithm [11], and parallel processing [12].

The completion of Portfolio Optimization with a mean-variance multiperiod method employed dynamic programming using the Bellman equation introduced by [4] with his work Optimal dynamic portfolio selection: multiperiod mean-variance formulation. In comparison, the discussion on pension funds is related to the risk of death and contribution changes [13] and [14]. And then (Yao, Lai, Ma \& Jian. 2014) conduct a discussion on asset allocation related to a defined contribution pension (Defined Contribute) using the multiperiod meanvariance method by considering death factors and the risk of change in contributions. This background becomes the basis for the author to discuss and find out more about the effect of mortality and changes in contributions to optimal asset allocation on defined contribution pension fund programs with mean-variance multiperiod methods using risk-free assets and risk assets in the capital market Indonesia.

\subsection{Theoretical Reviews}

In general, pension programs are sponsored by companies where employees work to ensure welfare for employees if they no longer work or retire and maintain the income of their employees or heirs if the employee becomes disabled or dies before retirement. Companies usually offer employees retirement money either a lump sum or annuity benefits or both at retirement. Some companies provide benefits simultaneously if employees die at work and are almost the same for life insurance benefits that involve long-term investment contributions. The pension program sponsored by the employer consists of two categories [15], namely:

1. Defined Benefit Pension Program (Defined Benefit). This program is associated with the period of employment, the last position, and the amount of our income to determine the amount of money received at retirement. The advantages of this program are that the pension is determined in advance according to the salary of the employee, so that the worker can determine the amount of money received at retirement age, retroactive, meaning that it can accommodate the work period that the employee has gone through after the company runs. While this program's weakness is that the company carries the risk of lack of funds if the investment returns are insufficient, and the program is relatively more challenging to manage in terms of administration.

2. Defined Contribute Pension Program, This pension program is extensive, or pension benefits are based on 
contributions paid by workers and companies (employers) monthly. The advantages of this program are that contributions from companies can be calculated with certainty, it is easier to calculate the number of contributions for workers so that the administrative process is also easier to manage. In comparison, this program's weakness is difficult to predict income when it reaches retirement age because employees bear the risk of investment failure and do not apply retroactively, meaning that they cannot accommodate the work period that the employee has passed.

Globally, the pension program with a defined benefit system has gradually been abandoned in many countries over the past few decades and has shifted towards a pension system for defined contribution benefits. In many countries, plans for pension plan contributions are used mainly by private companies. The transition from the defined benefit pension system to the defined contribution is not only carried out by the private sector, but the SME sector and households also follow the defined contribution pension scheme. With this condition, the impact of financial markets also affected the private sector and the SME sector, and households because the income at retirement received was also dependent on market conditions compared to before. These Conditions not only occur in countries with mature employment pension systems but also in developing countries [16].

From a long-term perspective, factors such as increased labor mobility related to demographic and industrial changes have also been driving drivers of trend changes from defined benefit pension plans to defined contributions. The defined benefit pension plan generally benefits employees who have a long service life, and because the defined benefit pension cannot be transferred from one company to another. The acceleration of the trend change from defined benefit pensions to defined contributions is also related to the increase in the burden of companies that have to cover the cost of pension benefits if the investments made are not as expected by moving to pension contributions certainly offering an easier way for companies to reduce the company's burden manage employee pension funds. The trend change from a defined benefit pension system to a fixed contribution also occurred in Indonesia. In the past five years, the number of pension fund participation dominated by DPLK using fixed contributions continues to show an increasing trend. This can be due to an increase in the company that includes its workers in the DPLK and the transfer of membership of DPPK to DPLK [1].

In Indonesia, Pension Funds are regulated based on Law Number 11 of 1992 concerning the Pension Fund. The Pension Fund also has a vital role as a local investor who has a significant contribution to government infrastructure development. The Pension Fund is one of the main buyers of Government Securities (SBN) issued by the government. Management of investments in Pension Funds must pay attention to the prevailing laws and regulations in addition to the regulations or decisions of the Founder of the Pension Fund as stated in the investment directives of each Pension Fund Institution. Both legislation and investment constraints set limits and targets for allocating the investment portfolio of the Pension Fund both qualitatively and quantitatively, which include both the type of investment and the limits and the level of liquidity in each type of investment.

\section{METHODS}

\subsection{Methodology Research}

This writing follows the same approach and notation from [3]. The steps and approaches to this writing are as follows:

Determine the research period for the allocation of assets in the next pension fund Determining the financial assets to be used in the formation of asset allocations in the portfolio is assumed that the asset allocation used consists of $n+1$ assets where the assets used can be either risk-free assets or all risky assets. 3. Look for returns and expected returns from each of these assets. This study's return uses a geometric average by comparing the price (P) in the $\mathrm{T}+1$ period with the $\mathrm{T}$ period an equation follow (1).

$$
\text { Return }=\frac{P(T+1)}{P(T)}
$$

Then the return will be denoted as (e). So that the asset return on portfolio $\mathrm{n}+1$ asset in period $\mathrm{k}$ is vector $e_{k}=\left(e_{k}^{0}, e_{k}^{1}, e_{k}^{2}, \ldots, e_{k}^{n}\right)^{\prime}$ where $\mathrm{k}=0,1,2, . . \mathrm{T}$ 1 and the sign 'is transpose from matrix or vector. Then the expected return and covariance $e_{k}$ an equation follow (2).

$$
E\left(e_{k}\right)=\left[E\left(e_{k}^{0}\right), E\left(e_{k}^{1}\right), \ldots E\left(e_{k}^{n}\right)\right]^{\prime}
$$

Obtain data on membership funds or contributions from employees in the study period. In this study, $x_{k}$ is a wealth terminal in each period, so that $x_{0}$ is called an initial fund. Whereas funds from employee contributions at the beginning of each period or year are $c_{k} * y_{k}$ where $c_{k}$ is the amount of contributions from employee salaries usually in percentages while $y_{k}$ is employee salaries at the beginning of each period, so $c_{0} * y_{0}$ is the initial contribution from employees. In this study, the value of $c_{k}=0.1$ is assumed because based on data obtained from the XYZ company, the percentage of contributions from employees' pension contributions is $10 \%$ of the salary received. So that the total funds held by pension fund institutions at the beginning of each period that can be reinvested are denoted as $z_{k}$ an equation follow (3).

$$
z_{k}=x_{k}+c_{k} y_{k}
$$


Determining the rate of change in employee contribution funds, in the period the contribution of pension funds to the company allows change to occur due to salary increases, employee promotions or inflation, the rate of change in employee income denoted as $q_{k}$ in period $\mathrm{k}=0,1, \ldots, \mathrm{T}-1$ is as follows (4).

$$
q_{k}=\frac{y_{k+1}}{y_{k}}
$$

The known contribution funds in each subsequent period will be invested in assets $n+1$ that have been predetermined during the period $\mathrm{k}$. The number of funds invested in the asset $\mathrm{i}$ is denoted $\mathrm{u}_{-} \mathrm{k}^{\wedge} \mathrm{i}$ where $\mathrm{k}=1 \ldots \mathrm{T}$ and $i=1,2,3 \ldots, n$. then the funds invested in the 0 th asset as a reference asset during period $\mathrm{k}$ are $(\mathrm{xk}+\mathrm{yk})$ -

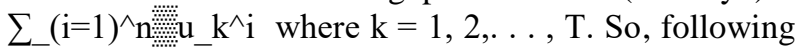
$(5)$.

$$
\begin{gathered}
\xi_{\kappa+1}=e_{k}^{0}\left(\left(\xi_{\kappa}+\chi_{\kappa} \psi_{\kappa}\right)-\sum_{i=1}^{n} u_{k}^{i}\right)+\sum_{i=1}^{n} e_{k}^{i} u_{k}^{i} \\
=\left(\xi_{\kappa}+\chi_{\kappa} \psi_{\kappa}\right) e_{k}^{0}+P_{k}^{\prime} u_{k}^{i}
\end{gathered}
$$

Where :

$P_{k}^{\prime}=\left(e_{k}^{1}-e_{k}^{0}, e_{k}^{2}-e_{k}^{0}, \ldots, e_{k}^{n}-e_{k}^{0}\right)^{\prime}$

$u_{k}^{i}=\left(u_{k}^{1}, u_{k}^{2}, \ldots u_{k}^{n}\right)^{\prime}$

Determining the mortality rate, in the period of pension fund contributions allowing an employee to die due to various things, his retirement plan must be terminated before retirement due to death's risk, future lifetime denoted by $\tau$ If the member dies during the time period $(\mathrm{k}-1)$. The time for the termination of the pension fund is $\mathrm{k}$, and if he dies after T-1, the time for stopping is $\mathrm{T} \tau=\mathrm{T}$ or if it is simplified as follows (6)

$$
T=\left\{\begin{array}{c}
k, k-1<\tau k \text { dan } 1 \leq k \leq T-1 \\
T, \tau>T-1
\end{array}\right\}(6)
$$

Following Yao, Lai, Ma \& Jian (2014), each period's mortality rate is constant force mortality. Content force mortality methods are also commonly used by actuaries in calculating mortality where the survival function (7).

$$
\left.\begin{array}{c}
T= \\
\exp \left(-\int_{0}^{k-1} \lambda(s) d s-\exp \left(-\int_{0}^{k} \lambda(s) d s, k=1, \ldots T-1\right.\right. \\
\exp \left(-\int_{0}^{T-1} \lambda(s) d s, \& k=T\right.
\end{array}\right\}
$$

Looking for efficient strategies and efficient frontiers based on the mean-variance model. The main purpose of this paper is to get optimal asset allocation with a meanvariance multiperiod method where the main purpose of pension fund institutions is how to get the minimum variance at the end of the period from the wealth terminal $\left(\llbracket \mathrm{x} \rrbracket_{-}\left(\square \mathrm{T} \tau \rrbracket^{\wedge}\right)\right)$ where expected terminal wealth is denoted as $\mathrm{d}$ if it is simplified as follows (8).

$$
\begin{gathered}
\operatorname{Min}_{u \in \theta 0}\left\{\operatorname{Var}\left[x_{T^{\tau}}\right]:=E\left[x_{T \tau}^{2}\right]-d^{2}\right\} \\
\text { s.t } E\left[x_{T \tau}\right]=d
\end{gathered}
$$

where :

$x_{T}=$ wealth terminal portofolio

$\mathrm{d}=$ return portofolio

The optimization model above when added a probability factor then equation (3.8) above is equivalent to the following model (Yao, Lai, Ma \& Jian, 2014) follow (9).

$$
\begin{gathered}
\operatorname{Min}_{u \in \theta 0}\left\{\operatorname{Var}\left[x_{T^{\tau}}\right]:=\mathrm{E}\left[\sum_{s=0}^{T} p_{s} x_{s}^{2}\right]-d^{2}\right\} \\
\text { s.t } E\left[\sum_{s=0}^{T} p_{s} x_{s}\right]=d
\end{gathered}
$$

To solve the optimization equation above with the $\mathrm{E}$ constraint $\mathrm{E}\left[\sum_{s=0}^{T} p_{s} x_{s}\right]=d$ can be solved using the Lagrange method. By adding a $2 \mu$ Lagrange multiplier so that the optimization equation solution above becomes follow (10).

$$
\begin{gathered}
\operatorname{Min}_{u \in \theta 0}\left\{\mathrm{E}\left[\sum_{s=0}^{T} p_{s} x_{s}^{2}\right]-d^{2}+2 \mu\left(\mathrm{E}\left[\sum_{s=0}^{T} p_{s} x_{s}\right]-\mathrm{d}\right\}\right. \\
\text { s.t } E\left[\sum_{s=0}^{T} p_{s} x_{s}\right]=d
\end{gathered}
$$

The above equation can be simplified as follows (11).

$$
\begin{gathered}
\operatorname{Min}_{u \in \theta 0}\left\{E\left[\sum_{s=0}^{T}\left(p_{s} x_{s}^{2}+2 \mu p_{s} x_{s}\right]-d^{2}-2 \mu d\right\}\right. \\
\text { s.t } E\left[\sum_{s=0}^{T} p_{s} x_{s}\right]=d \\
)
\end{gathered}
$$

Where if $\left(d^{2}-2 \mu d\right)$ is a fixed value then the optimization equation model solution above becomes follow (12).

$$
\begin{gathered}
\operatorname{Min}_{u \in \theta 0} E\left[\sum_{s=0}^{T}\left(p_{s} x_{s}^{2}+2 \mu p_{s} x_{s}\right]\right. \\
\text { s.t } \mathrm{E}\left[\sum_{s=0}^{T} p_{s} x_{s}\right]=d
\end{gathered}
$$

Using equation (3) into equation (12), the equation becomes (13).

$$
\begin{gathered}
\operatorname{Min}_{u \in \theta 0} E\left[\sum_{s=0}^{T}\left(p_{s}\left(z_{s}-c_{s} y_{s}\right)^{2}+2 \mu p_{s}\left(z_{s}-c_{s} y_{s}\right)\right]\right. \\
\text { s.t } \mathrm{E}\left[\sum_{s=0}^{T} p_{s} x_{s}\right]=d
\end{gathered}
$$


Solving the above equation to get optimal results at the end of the period requires an approach to dynamic programming. Where the model of pension contributions in each period for dynamic programming can be described as follows Figure 1.

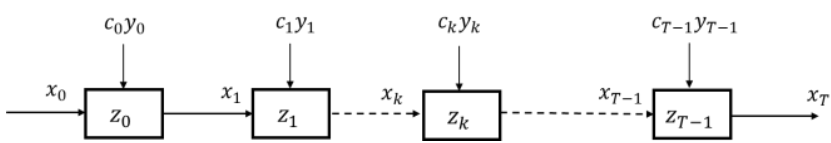

Figure 1. Dynamic programming model.

By using the Bellman equation, the equation for optimization of terminal wealth in period $\mathrm{k}$ is as follows the equation.

$$
\begin{gathered}
f_{k}\left(z_{k}, y_{k}\right)=\operatorname{Min} E\left[p_{k}\left(z_{k}-c_{k} y_{k}\right)^{2}\right. \\
+2 \mu p_{k}\left(z_{k}-c_{k} y_{k}\right) \\
\left.+f_{k+1}\left(z_{k+1}-y_{k+1}\right)\right] \\
f_{T}\left(z_{T}, y_{T}\right)=p_{T}\left(z_{T}-c_{T} y_{T}\right)^{2} \\
+2 \mu p_{T}\left(z_{T}-c_{T} y_{T}\right)
\end{gathered}
$$

To solve the dynamic programming equation, the above equation is divided into several new backward iteration series $\omega_{k}, h_{k}, \alpha_{k}, \lambda_{k}, \gamma_{k}$ and $g_{k}$. Where the equation in each of the backward series of iterations is as follows (14).

a. Deret backward $\omega_{k}$ : $\omega_{k}=p_{k}+\omega_{k+1} A_{k}, \ldots$

with $\mathrm{k}=0,1, \ldots T-1$

Where :

$$
\omega_{T}=p_{T}, \quad \text { with } \mathrm{k}=T
$$

$$
A_{k}=E\left[\left(e_{k}^{0}\right)^{2}\right]-E\left[e_{k}^{0} P_{k}^{\prime}\right] E^{-1}\left[P_{k} P_{k}^{\prime}\right] E\left[e_{k}^{0} P_{k}\right]
$$

b. Deret backward $h_{k}$ :

$$
\begin{gathered}
h_{k}=p_{k}+h_{k+1} J_{k}, \\
h_{T}=p_{T},
\end{gathered}
$$
with $\mathrm{k}=T$

Where:

$$
J_{k}=E\left[e_{k}^{0}\right]-E\left[e_{k}^{0} P_{k}^{\prime}\right] E^{-1}\left[P_{k} P_{k}^{\prime}\right] E\left[P_{k}\right]
$$

c. Deret backward $\alpha_{k}$ :

$$
\begin{gathered}
\alpha_{k}=\alpha_{k+1}-\frac{h_{k+1}^{2}}{\omega_{k+1}} D_{k}, \\
\alpha_{T}=0
\end{gathered}
$$

with $\mathrm{k}=0,1, \square T-1$

Where:

$$
D_{k}=E\left[P_{k}^{\prime}\right] E^{-1}\left[P_{k} P_{k}^{\prime}\right] E\left[P_{k}\right]
$$

d. Deret backward $\lambda_{k}$ :

$$
\begin{gathered}
\lambda_{k}=\lambda_{k+1} C_{k}-p_{k} c_{k}+\omega_{k+1} c_{k+1} C_{k}, \\
\text { with } \mathrm{k}=0,1, \ldots \mathrm{T}-1
\end{gathered}
$$

Where:

$$
C_{k}=E\left[e_{k}^{0} q_{k}\right]-E\left[e_{k}^{0} P_{k}^{\prime}\right] E^{-1}\left[P_{k} P_{k}^{\prime}\right] E\left[q_{k} P_{k}\right]
$$

e. Deret backward $\gamma_{k}$ :

$$
\begin{gathered}
\gamma_{k}=\gamma_{k+1} E\left[q_{k}^{2}\right]+p_{k} c_{k}^{2} \\
+\left(\omega_{k+1} c_{k+1}+2 \lambda_{k+1}\right) c_{k+1} B_{k} \\
-\frac{\lambda_{k+1}^{2}}{\omega_{k+1}}\left(E\left[q_{k}^{2}\right]-B_{k}\right), \text { with } \mathrm{k}=0,1, \ldots T-1 \\
\gamma_{T}=c_{T}^{2} p_{T}, \text { with } \mathrm{k}=T
\end{gathered}
$$

Where :

$$
B_{k}=E\left[q_{k}^{2}\right]-E\left[q_{k} P_{k}^{\prime}\right] E^{-1}\left[P_{k} P_{k}^{\prime}\right] E\left[q_{k} P_{k}\right]
$$

f. Deret backward $\gamma_{k}$ :

$$
\begin{gathered}
g_{k}=g_{k+1} E\left[q_{k}\right]-p_{k} c_{k}+h_{k+1}\left(c_{k+1} M_{k}\right)- \\
\frac{\lambda_{k+1}}{\omega_{k+1}}\left(E\left[q_{k}\right]-M_{k}\right) \quad \text { with } k=0,1, \ldots T-1 \\
g_{T}=-c_{T} p_{T} \quad \text { with } \mathrm{k}=\mathrm{T}
\end{gathered}
$$

Where :

$$
M_{k}=E\left[q_{k}\right]-E\left[q_{k} P_{k}^{\prime}\right] E^{-1}\left[P_{k} P_{k}^{\prime}\right] E\left[P_{k}\right]
$$

To speed up the backward iteration process above using a software statistic $\mathrm{R}$ where the results of these calculations will be obtained parameters needed to obtain efficient investment by using the following (20).

$$
\begin{gathered}
u_{k}^{*}=-E^{-1}\left[P_{k} P_{k}^{\prime}\right]\left\{\left(x_{k}+y_{k}\right) E\left[u_{k}^{0} P_{k}\right]+y_{k}(1+\right. \\
\left.\left.\frac{\lambda_{k+1}}{\omega_{k+1}}\right) E\left[q_{k} P_{k}\right] \frac{\left(h_{0}\left(x_{0}+y_{0}\right)+g_{0} y_{0}-d\right) h_{k+1}}{\alpha_{0} \omega_{k+1}} E\left[P_{k}\right]\right\}
\end{gathered}
$$

Then the previously known parameters can be used to obtain portfolio variance by using the following (21).

$$
\begin{gathered}
\operatorname{Var}\left[x_{T^{\tau}}\right]=\frac{1}{1+\alpha_{0}}\left(d-\frac{h_{0}\left(x_{0}+y_{0}\right)+g_{0} y_{0}}{1+\alpha_{0}}\right)^{2}+ \\
\omega_{0}\left(x_{0}+c_{0} \frac{\left.y_{0}\right)^{2}+2 \lambda_{0}\left(x_{0}+y_{0}\right) y_{0}+\gamma_{0} y_{0}^{2}-}{\frac{1}{1+\alpha_{0}}\left(h_{0}\left(x_{0}+y_{0}\right)+\right.}\right. \\
\left.g_{0} y_{0}\right)^{2}
\end{gathered}
$$

To get the Global Minimum Variance (GMV) then $d$ $=d_{\sigma \min }==\frac{\left(h_{0}\left(x_{0}+c_{0} y_{0}\right)+g_{0} y_{0}\right)}{1+\alpha_{0}}$

so that a new equation is obtained follow (22).

$$
\begin{aligned}
& \operatorname{Var}_{\min }\left[x_{T^{\tau}}\right]=\omega_{0}\left(x_{0}+y_{0}\right)^{2}+2 \lambda_{0}\left(x_{0}+\right. \\
& \left.\quad y_{0}\right) y_{0}+\gamma_{0} y_{0}^{2}-\frac{1}{1+\alpha_{0}}\left(h_{0}\left(x_{0}+y_{0}\right)+\right. \\
& \left.g_{0} y_{0}\right)^{2}
\end{aligned}
$$

From equation (19) above, it can be used to form an efficient frontier described in the form of a curve for the efficient frontier.

\section{RESULTS AND DISCUSSION}

\subsection{Result}

The asset allocation model for Pension Funds with the multiperiod mean-variance method in this study uses several asset allocation scenarios under the main writing objectives by considering mortality factors and changes 
in contributions. In accordance with the research method, assets that will use 10 stocks from the LQ45 index have the best return. Based on the results of the study, it is known that the 10 best stocks to be used are AALI, BBNI, BBRI, GGRM, ICBP, JSMR, KLBF, PTBA, UNVR. The multiperiod mean-variance method requires an asset reference where the asset reference $\left(\mathrm{e}_{-} \mathrm{k}^{\wedge} 0\right)$ used in this writing is TLKM shares or Treasury Bills (SPN) 3 months. Based on the TLKM stock research results chosen as an asset reference because it has the least variance value or risk compared to other stocks, it is very suitable to be used as an asset reference.

\section{Asset Allocation Model with Mortality, Fee Changes and Risky Assets (Scenario 1)}

The asset allocation model (Scenario 1) will consider several risk factors: mortality, membership fees, and risky assets. According to the initial planning of asset allocation, used is as many as 10 shares or risky assets with a duration of 5 periods from 2014-2018. In this scenario, the initial fund was $x_{0}=1.08$, and the percentage of membership contributions of $10 \%$ of income or $c_{k}=0.1$ paid at the beginning of each period. Where when using $d_{\sigma \min }=3,055$, we can obtain wealth ( UK) and efficient investment strategy ( UK) in each period using formulas (5) and (20) and asset allocation at the beginning of each period as follow table 1 .

Table 1. Asset Allocation with Mortality and Fee Changes

\begin{tabular}{|l|l|l|l|l|l|}
\hline $\mathbf{k}$ & $\mathbf{0}$ & \multicolumn{1}{|c|}{$\mathbf{1}$} & \multicolumn{1}{|c|}{$\mathbf{2}$} & \multicolumn{1}{|c|}{$\mathbf{3}$} & \multicolumn{1}{|c|}{} \\
\hline $\boldsymbol{U} \boldsymbol{k}$ & 0.89 & 6.07 & 10.40 & 14.10 & 12.90 \\
\hline $\boldsymbol{X} \boldsymbol{k}$ & 1.08 & 1.66 & 2.19 & 2.71 & 2.95 \\
\hline & & & & & \\
\hline Aset & $\mathbf{2 0 1 4}$ & $\mathbf{2 0 1 5}$ & $\mathbf{2 0 1 6}$ & $\mathbf{2 0 1 7}$ & $\mathbf{2 0 1 8}$ \\
\hline $\boldsymbol{T L K M}$ & 0.41 & -4.17 & -7.95 & -11.12 & -9.65 \\
\hline $\boldsymbol{A D R \boldsymbol { O }}$ & 0.30 & 0.26 & 0.23 & 0.24 & 0.37 \\
\hline $\boldsymbol{B B N I}$ & 1.60 & -8.97 & -17.69 & -24.61 & -21.05 \\
\hline $\boldsymbol{B B R I}$ & -0.97 & 7.36 & 14.25 & 19.74 & 17.07 \\
\hline $\boldsymbol{G G R \boldsymbol { M }}$ & -0.89 & 8.42 & 16.14 & 22.30 & 19.38 \\
\hline $\boldsymbol{I C B P}$ & 2.11 & -4.65 & -10.20 & -14.51 & -11.82 \\
\hline $\boldsymbol{J S M R}$ & 0.02 & -7.53 & -13.82 & -18.91 & -16.84 \\
\hline $\boldsymbol{K L B \boldsymbol { F }}$ & -1.17 & 9.42 & 18.19 & 25.19 & 21.84 \\
\hline $\boldsymbol{P T B \boldsymbol { A }}$ & --0.57 & -0.87 & -1.14 & -1.41 & -1.57 \\
\hline $\boldsymbol{U N V \boldsymbol { R }}$ & 0.46 & 2.63 & 4.46 & 5.97 & 5.53 \\
\hline
\end{tabular}

From the table above, it can be obtained some analysis that by using TLKM asset reference, it is known that wealth at the beginning of the period $x_{0}=1.08$ continues to grow from each period so that at the end of the fifth-period wealth terminal is $d=3.055$ or expected return of $25 \%$ per year. Furthermore, by using the multiperiod mean-variance formula (3.21), the variance equation and efficient frontier obtained at the end of the seams period are obtained as follows.

Var $=0.770(d-3.055)^{2}-1.886$

\section{Asset Allocation without Employee Contributions (Scenario 2)}

In this asset allocation model, without any additional membership contributions from employees in each period, so the membership funds used only use the initial funds $x_{0}=1.08$ from the company. This model still considers other risk factors such as mortality, the assets used, and all risky assets. With this condition, the percentage of employee membership contributions is zero or $\mathrm{CK}=0$. Data for market parameters have no change because pension fund membership contributions do not affect market changes but only affect the backward series parameters.

Where when using $d_{\text {бmin }}=1.60$ can be obtained wealth ( $\mathrm{CK}$ ) and efficient investment strategy ( UK) in each period using formula (3.5) and (3.20), the asset allocation at the beginning of each period is obtained as follows table 2 .

Table 2. Non-Contribution Asset Allocation for each Period

\begin{tabular}{|l|l|l|l|l|l|}
\hline $\mathbf{k}$ & \multicolumn{1}{|c|}{$\mathbf{0}$} & \multicolumn{1}{|c|}{$\mathbf{2}$} & \multicolumn{1}{|c|}{$\mathbf{2}$} & \multicolumn{1}{|c|}{$\mathbf{3}$} \\
\hline $\boldsymbol{U} \boldsymbol{k}$ & 3.70 & 5.37 & 6.38 & 7.09 & 5.99 \\
\hline $\boldsymbol{X} \boldsymbol{k}$ & 1.08 & 1.30 & 1.47 & 1.62 & 1.54 \\
\hline & & & & & \\
\hline Aset & $\mathbf{2 0 1 4}$ & $\mathbf{2 0 1 5}$ & $\mathbf{2 0 1 6}$ & $\mathbf{2 0 1 7}$ & $\mathbf{2 0 1 8}$ \\
\hline $\boldsymbol{T L K M}$ & -2.62 & -4.08 & -4.92 & -5.47 & -4.45 \\
\hline $\boldsymbol{A D R \boldsymbol { O }}$ & 0.15 & 0.14 & 0.15 & 0.18 & 0.21 \\
\hline $\boldsymbol{B B N \boldsymbol { I }}$ & -5.58 & -8.91 & -10.81 & -8.72 & -9.43 \\
\hline $\boldsymbol{B B R \boldsymbol { I }}$ & 4.57 & 7.21 & 8.72 & 7.10 & 7.68 \\
\hline $\boldsymbol{G G R \boldsymbol { M }}$ & 5.22 & 8.17 & 9.87 & 8.08 & 8.75 \\
\hline $\boldsymbol{I C B P}$ & -2.95 & -5.06 & -6.23 & -4.80 & -5.16 \\
\hline $\boldsymbol{J S M R}$ & -4.65 & -7.07 & -8.48 & -7.09 & -7.69 \\
\hline $\boldsymbol{K L B \boldsymbol { B }}$ & 5.86 & 9.22 & 11.14 & 9.09 & 9.84 \\
\hline $\boldsymbol{P T B \boldsymbol { A }}$ & -0.52 & -0.63 & -0.71 & -0.71 & -0.78 \\
\hline $\boldsymbol{U N \boldsymbol { N } \boldsymbol { R }}$ & 1.59 & 2.30 & 2.72 & 2.36 & 2.58 \\
\hline
\end{tabular}

From the table above, we can obtain some analysis that wealth continues to grow from each period even though the condition of the Indonesian stock market decreased in 2015 , but at the end of the fifth period, the expected terminal wealth is $d_{\text {omin }}=1.60$ or the expected return of $9.8 \%$ per year. Furthermore, from the multiperiod mean-variance formulation (21), the following variance and efficient frontier equations are obtained.

$$
\operatorname{Var}=0.77(\mathrm{~d}-1.60) 2+0.105
$$

From the above equation, the minimum variance or global minimum variance is obtained if the value of $d_{\text {omin }}=1.6$ so that the variance value is 0.105 , this value is greater than the asset allocation if there are additional membership contributions from employees because the amount of funds that can be invested is more limited. but the risk in this model is higher than the first asset allocation model because, in this model, there are still market risk factors and mortality that influence 


\section{Asset Allocation without Risk of Mortality (Scenario 3)}

In this asset allocation model, considering asset allocation without mortality factors, it is still considering other risk factors such as changes in employees' contributions with the assets used are all risky assets. With this condition, the mortality for period 0 - T-1 will be worth 0 while at the time of period $\mathrm{T}=1$. Where when using $E\left[x_{T}\right]=d_{\sigma \min }=4.07$ at the end of the fifth-period wealth $\left(x_{k}\right)$ and efficient investment strategy can be obtained $(U K)$ at the beginning of each period using formulas (8) and (23), the asset allocation will be obtained at the beginning of each period as follows table 3 .

Table 3. Asset Allocation without Mortality every Period

\begin{tabular}{|c|c|c|c|c|c|}
\hline $\mathbf{k}$ & 0 & 1 & 2 & 3 & 4 \\
\hline$U k$ & -0.245 & -0.719 & -1.128 & -1.45 & -1.198 \\
\hline$X k$ & 1.080 & 1.494 & 1.867 & 2.2 & 2.53 \\
\hline Aset & 2014 & 2015 & 2016 & 2017 & 2018 \\
\hline$S P N$ & 1.543 & 2.450 & 3.251 & 3.928 & 4.025 \\
\hline TLKM & -1.368 & -1.810 & -2.209 & -2.563 & -2.872 \\
\hline ADRO & 0.536 & 0.642 & 0.740 & 0.834 & 0.938 \\
\hline BBNI & 1.233 & 1.456 & 1.666 & 1.834 & 0.938 \\
\hline BBRI & -0.518 & -1.136 & -1.673 & -2.108 & -2.352 \\
\hline GGRM & 1.019 & 1.330 & 1.612 & 1.867 & 2.109 \\
\hline ICBP & 1.736 & 1.769 & 1.825 & 1.930 & 2.221 \\
\hline JSMR & -0.725 & -0.450 & -0.227 & -0.083 & -0.152 \\
\hline$K L B F$ & -0.594 & -0.662 & -0.730 & -0.805 & -0.928 \\
\hline PTBA & -0.901 & -1.031 & -1.155 & -1.283 & -1.453 \\
\hline UNVR & -0.664 & -0.828 & -0.978 & -1.114 & -1.236 \\
\hline
\end{tabular}

From the table above, it can be obtained some interesting information that by using the reference assets of the 3-month SPN as a risk-free asset, it is known that wealth at the beginning of the period or initial fund $x_{0}=$ 1.08 continues to grow in each period despite fluctuating market conditions. However, this does not affect the wealth growth of pension funds. Thus, at the end of the fifth period, the wealth terminal obtained at $d_{\sigma \min }=2.60$ or the expected return of $21 \%$ per year.

\subsection{Reviews}

The pension fund program is a long-term investment program with characteristics in which the period of the contribution of participant contributions is generally long, due to economic conditions and prospects for promotion allowing employee income to change in each period so that contributions from pension contributions also change in each period. During the process of the pension fund program, it is also possible to stop the pension program either due to retirement employees or due to mortality due to various causes of death. Based on this reality, the Pension Fund institution must be able to understand other risk factors outside of market risk that can affect the return on investment in the Pension Fund.
The asset allocation method, which is generally known, still uses Markowitz's method, namely the mean-variance method. The method introduced by Markowitz is the asset allocation method for a single period. Based on these conditions, Markowitz's method is less able to capture existing reality mainly because mortality factor. Although this research is limited to only five years, it is expected to get an overview of the effects of mortality and the global economy, especially the stock market, on Pension Funds' investment growth. Then, based on the results carried out on various asset allocation scenarios using the multiperiod mean-variance method by adding contribution and mortality factor changes according to the reality that occurs, if the curves of all the efficient frontier curves at the end of the fifth period of various asset allocation scenarios, it can be described as in the graph as follows fig. 2 .

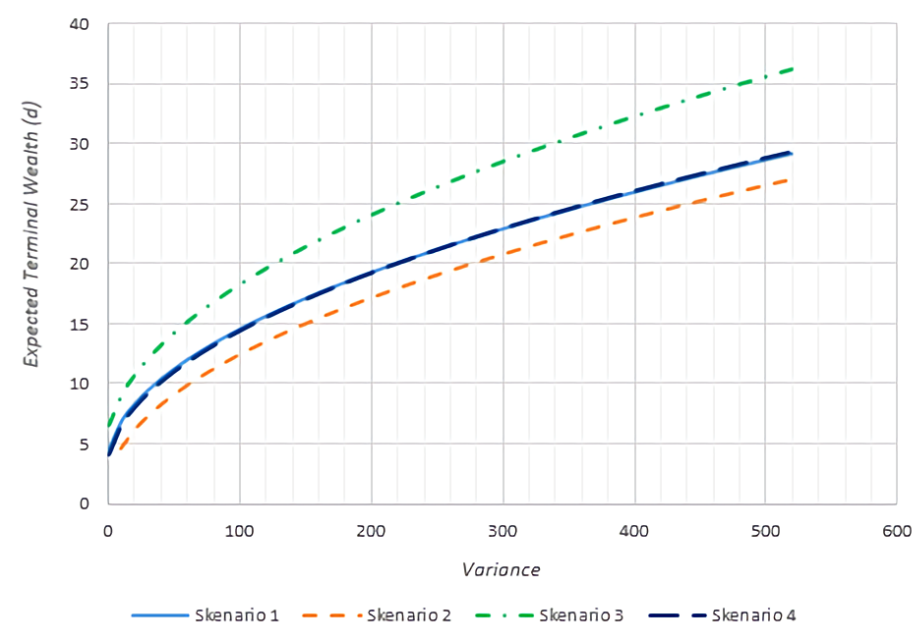

Figure 2. Comparison of efficient frontier of all scenarios

From the Figure above, it can be seen that in an asset allocation model, scenario 2 has the smallest expected terminal wealth for the same risk. This can be easily understood because, without additional membership fees paid by employees at the beginning of each period, the funds received by the Pension Fund for more limited investment needs are shown in table (2), with the investment funds owned smaller. To obtain minimal risks with optimal returns at the end of the period, the funds invested are limited. The return obtained in the asset allocation model for scenario 2 is smaller compared to other asset allocation models coupled with the existence of mortality factors. Later, it causes the investment period to be more limited because there is a possibility that pension programs are forced to stop before retiring due to mortality factors.

Then figure 1 above shows that in the asset allocation model, scenario 3 has the highest expected terminal wealth for the same risk compared to other asset allocation models because in the asset allocation model 
in scenario 3 there is only a market risk that affects without the risk of mortality, so the return obtained can be higher than other asset allocation models. Besides being only influenced by market risk factors, the strategy used in the multiperiod mean-variance method uses an active asset allocation strategy. It can be seen that in each period, the Pension Fund must conduct a short-sale to obtain the minimum risk with the expected terminal wealth optimal at the end of the investment period or the fifth period. To get the optimal expected terminal wealth at the end of the fifth-period, an efficient strategy ( UK) is greatly needed than the wealth value $\left(\mathrm{x} \_\mathrm{k}\right)$ owned to buy additional assets other than the asset reference. This applies to all asset allocation models that use asset references other than risk-free assets. This is because it is influenced by the asset reference characteristics used in this writing using TLKM as a reference for its assets. Although TLKM has a small variance compared to other assets, each return period obtained by TLKM fluctuate and has a downward trend. This condition causes the required amount of funds to obtain the optimal, efficient investment strategy ( UK). This condition is shown that efficient investment strategy ( UK) the greater the period, the greater the risk and optimal wealth terminal at the end of the investment period.

From Figure 1 above, it also looks interesting that the graph of the efficient frontier for the asset allocation model between scenario 1 and 4 coincides with this condition because the factors of asset reference characteristics used together have a small variance value, even though expected terminal wealth for the asset allocation model scenario 1 is bigger. However, the value is not quite far enough with the asset allocation model scenario 4. In this condition, it can be concluded that the asset reference factor in the multiperiod mean-variance method influences the expected terminal wealth at the end of the investment period. Nevertheless, there is a difference that is in the asset allocation model for the fourth model, the number of asset reference values , i.e., SPN 3 months at the beginning of each period, continues to increase and gets a greater proportion than other assets. This is due to the characteristics of the 3-month SPN, which has variance very small and definite return so that by adding risk-free assets as asset references in the portfolio, the amount of asset allocation for risk-free assets is chosen because it has the least risk and a definite return compared to other assets. This condition is strengthened from table 4.16, where to obtain The optimal expected terminal wealth at the end of the fifth period requires a less efficient investment strategy ( UK) compared to the wealth value $\left(x_{k}\right)$. This condition indicates that using risk-free assets as asset references in the portfolio does not require a lot of additional funds to buy assets other than Outside reference assets to obtain a minimal variance and optimal return at the end of the period.

\section{CONCLUSIONS}

Based on the results of pension fund investment asset allocation research using several asset allocation model scenarios using the multiperiod mean-variance method by considering mortality factors and changes in membership contributions, can be drawn some conclusions:

The asset allocation model in scenario 1 considers the change factor of membership contribution and mortality factor with all asset allocations using risky assets or stocks at the minimum global variance point at the end of the fifth period resulting in an expected return of $25 \%$.

The asset allocation model in scenario 2, which only considers mortality without the addition of membership contributions for each period with all asset allocations using risky assets or shares at the minimum global variance at the end of the fifth period, produces the least expected return compared to all other asset allocation models $9.8 \%$. This is because, without additional contributions in each period, the funds that can be allocated for each period are more limited so that the return obtained is smaller.

The asset allocation model in scenario 3 without considering the mortality factor with all asset allocations using risky-assets or stocks at the minimum global variance point at the end of the fifth period produces the highest expected return than all other asset allocation models, which is $32 \%$. This is because in the asset allocation model this scenario, there is only market risk, so that without the risk of mortality that affects the return obtained can be higher than other asset allocation models.

Asset allocation model in scenario 4 by using asset references using risk-free assets of 3 months SPN by considering mortality and membership fees yield an expected return of $21 \%$ where the expected return is not sufficiently far from the asset allocation model scenario 1. In this model, it is known that asset reference factors in the multiperiod mean-variance method affect the expected terminal wealth at the end of the investment period. In addition, this model shows that using risk-free assets as an asset reference does not require a lot of additional funds to buy other assets other than reference assets to obtain a minimal variance and optimal return at the end of the period.

\section{REFERENCES}

[1] OJK, "Laporan tahunan otoritas jasa keuangan," 2017. http: www.ojk.go.id/id/ data-dan-statistik /laporan-tahunan/Pages.

[2] OJK, "Buku dana pensiun," 2016. https://www.ojk.go.id/id/kanal/iknb/data-dan$\% 09$ statistik/dana pensiun/Documents/Pages/BukuStatistik-Dana-Pensiun-2016. 
[3] H. Yao, Y. Lai, Q. Ma, and M. Jian, "Asset allocation for a DC pension fund with stochastic income and mortality risk: a multi-period meanvariance framework," Insur. Math. Econ., vol. 54, no. 1, 2014, doi: 10.1016/j.insmatheco.2013.10.016.

[4] D. Li and W. L. Ng, "Optimal dynamic portfolio selection: multiperiod mean-variance formulation," Math. Financ., vol. 10, no. 3, 2000, doi: 10.1111/1467-9965.00100

[5] H. Markowitz, "Portfolio selection harry markowitz,” J. Finance, vol. 7, no. 1, 1952.

[6] G. J. Alexander, W. F. Sharpe, and J. V. Bailey, Fundamental of investment. 2003.

[7] W. G. Zhang and Y. J. Liu, "Credibilitic meanvariance model for multi-period portfolio selection problem with risk control," OR Spectr., vol. 36, no. 1, 2014, doi: 10.1007/s00291-013-0335-6.

[8] Asosiasi Dana Pensiun Indonesia, "Buku pedoman investasi asosiasi dana pensiun indonesia," 2013. http://www.adpi.or.id/aboutus/16/kumpulanperatura n-dana-pensiun.

[9] J. Qi and L. Yi, "Multi-period portfolio selection with no-shorting constraints: duality analysis," J. Math. Financ., vol. 07, no. 03, 2017, doi: 10.4236/jmf.2017.73040.
[10] C. J. Chen and S. Zionts., "The optimal portofolio revision policy,” J. Bus., no. 44, pp. 51-61, 1971.

[11]F. Cong and C. W. Oosterlee, "Multi-period meanvariance portfolio optimization based on montecarlo simulation," J. Econ. Dyn. Control, vol. 64, 2016, doi: 10.1016/j.jedc.2016.01.001.

[12]R. Östermark, "Massively parallel processing of recursive multi-period portfolio models," Eur. J. Oper. Res., vol. 259, no. 1, 2017, doi: 10.1016/j.ejor.2016.10.009.

[13]D. Hainaut and P. Devolder, "Management of a pension fund under mortality and financial risks," Insur. Math. Econ., vol. 41, no. 1, 2007, doi: 10.1016/j.insmatheco.2006.10.014.

[14]R. Josa-Fombellida and J. P. Rincón-Zapatero, "Mean-variance portfolio and contribution selection in stochastic pension funding," Eur. J. Oper. Res., vol. 187, no. 1, 2008, doi: 10.1016/j.ejor.2007.03.002.

[15] D. C. M. Dickson, M. R. Hardy, and H. R. Waters, Actuarial mathematics for life contingent risks. 2019.

[16] G. Impavido, E. Lasagabaster, and M. GarcíaHuitrón, New policies for mandatory defined contribution pensions. 2010. 